\title{
CHAPTER 62
}

\section{Barcelona}

\section{Miguel Picornell and Maxime Lenormand}

The Barcelona scenario is one of the three case studies (together with London and Zürich) carried out under the framework of the EUNOIA (Evolutive User-centric Networks fOr Intraurban Accessibility) project. The main goal of the Barcelona case study was to evaluate the impact of different public bike-sharing schemes in the city. The study area covers the metropolitan Barcelona area, with special focus on the city center, where public bike-sharing stations are located. For this study a novel bike-sharing module was developed by ETH Zürich.

\subsection{Transport Supply: Network and Public Transport}

The road network was extracted from the TransCAD (Transportation Computer Assisted Design) model used by the city of Barcelona. Public transport supply was also considered, comprising: bus, underground, tram, train and bike-sharing. Information about stops and schedules was obtained from the public information available at the Barcelona Open Data platform, as well as from the Barcelona transport authority website.

\subsection{Transport Demand: Population}

Agent plans were defined using anonymised mobile phone registers CDRs (Call Detail Records). From mobile phone data, it is possible to identify places where agents perform activities and corresponding trips. Activities have been classified as "home", "work" and "other" (including as "other", "leisure", "shopping", etc.). A sample of around $15 \%$ of the population was used in the simulation. Modes used in the simulation model include: walking, cycling, public transport and car.

\section{How to cite this book chapter:}

Picornell, M and Lenormand, M. 2016. Barcelona. In: Horni, A, Nagel, K and Axhausen, K W. (eds.) The MultiAgent Transport Simulation MATSim, Pp. 397-398. London: Ubiquity Press. DOI: http://dx.doi.org/ 10.5334/baw.62. License: CC-BY 4.0 


\subsection{Calibration and Validation}

Different data sources were used to calibrate and validate the model. First, to validate agent plans obtained from mobile phone data, results were compared to EMEF (Enquesta de Mobilitat en dia Feiner), indicating that mobile phone data provides information similar to traditional surveys. Additionally, agents' utility function was calibrated using the modal split from EMEF and road counts.

\subsection{Results and More Information}

At the time this summary was written, the calibration process was still ongoing. More detailed information about the scenario and main results can be found at: http://www. eunoia-project. eu/publications/ (project deliverables/Report on Case Study 3: Barcelona). 